\title{
Impact of Murraya koenigii (L.) Sprengel (Rutaceae) extracts on lifespan and oxidative stress markers in Drosophila melanogaster Meigen, 1830 (Diptera)
}

\section{Dinesh Kumar' ${ }^{1}$, Sunita $^{2}$ and Veer Bhan ${ }^{1}, *$}

${ }^{1}$ University Institute of Engineering and Technology. Maharshi Dayanand University. Department of Biotechnology. Rohtak-124001, India. *Email: dineshbhatti1@gmail.com.

${ }^{2}$ Pt. Neki Ram Sharma Govt. College. Delhi Road Near Power House Rohtak. Rohtak, India.

\begin{abstract}
The free radicals (ROS and RNS) damage to proteins, DNA, lipids of the cell. These free radicals creates the imbalance in physiological functions and acts as a prevalent cause of various diseases such as cancer, diabetes, cardiovascular diseases, aging, oxidative stress and metabolic syndrome by dysfunction of antioxidant enzyme system of cell. Using the fruit fly Drosophila melanogaster Meigen, 1830 (Diptera) as a model we examined the antioxidant properties of Murraya koenigii (L.) Sprengel (Rutaceae) on the life history parameters. We demonstrate a novel physiological interaction between free radicals, oxidative stress and antioxidant enzyme system by using extracts of $M$. koenigii in standard diet of the fly. This study describes how this interaction impacts a very early cellular defect associated with ageing and ageing associate diseases. We also describe progressive deficits in flies expressing the superoxide dismutase gene, catalase and lipid peroxidation. Collectively, our work demonstrates that Drosophila can be used to study the cellular, physiological and behavioral basis of human ageing related diseases.
\end{abstract}

Keywords: Murraya koenigii; Antioxidant enzyme system; Superoxide dismutase; Catalase and lipid peroxidation.
Received

November 7, 2019

Accepted

March 27, 2020

Available on line on

April 7, 2020

Released

April 30, 2020

Full Text Article

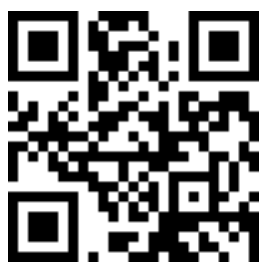

(D) 0000-0002-7708-3743

Dinesh Kumar

(D) 0000-0001-5203-717X

Sunita

D 0000-0001-9212-2862

Veer Bhan 


\section{Introduction}

Drosophila Fallén, 1823 is a model organism to study various diseases including neurodegenerative, cardiovascular, T2D and also aging related diseases. The effect of the chemically unstable free radicals may cause damage to the proteins, DNA, lipids of the that created by imbalance between the generation of reactive oxygen species (ROS) and the antioxidant enzymes. These free radicals are generated at low level during physiological functions and metabolic activities of the body. These radicals include reactive oxygen species (superoxide and hydroxyl anions) and reactive nitrogen species (nitric oxide). Antioxidants of natural and synthetic origin prevents the free radical damage by scavenging of these radicals (Gutteridge and Halliwell, 2000). Studies on several synthetic antioxidants revals that BHA and BHT reported as toxic. The requirement towards natural antioxidant has play attention and also different kinds of plants have been proved as source of natural antioxidant.

Murraya koenigii (L.) Sprengel plant belongs to the Family Rutaceae. It is a shurbaceous, semidecidous strong woody plant founds in India and other Asian countries. It is locally dilects known as curry leaf or meetha neem plant due to presence of pleasant aromatic smell, ornament creature and also used as a spicing flavoring agent for various food and home made preparations. It is also used in Indian cookry for centuries and have a versatile nature with their tonic and stomactic properties. Bark and roots are used as stimulant and also in bites of poisoness animals externally. This has been reported to have antioxidative, antimicrobial, antibacterial and anticholesterol properties (Jain et al., 2012). The other phytochemicals isolated and characterized from the leaves are alkaloids such as mahanine, koenine, koenigine, koenidine, girinimbiol, girinimibine, koenimbine, 0-methyl murrayamine A, O-methyl mahanine, isomahanine, bismahanine, bispyrayafoline (Zahin et al., 2013; Devatkal et al., 2012; Sindhu et al., 2012).

In this study we have evaluated the anti oxidant effect of $M$. koenigii to suppress the effect of oxidative stress in the form of free radicals in the D. melanogaster (Bilen, 2005; Jafari, 2010).

\section{Material and methods}

\section{Fly strain and culture}

The wild type Drosophila melanogaster was used for all experiments captured from fruit market of Shimla, Himachal Pradesh (India) and larvae of D. melanogaster (wild type) were reared at $21{ }^{\circ} \mathrm{C}$ on a standard Drosophila diet containing agar-agar, maize powder, sugar, yeast, sodium benzoate as antifungal and propionic acid as antibacterial agent. For healthy growth of the organism, additional live yeast suspension was provided.

\section{Plant collection and Extraction procedure}

The plant Murraya koenigii personally collected from the plane area of Haryana (India) and were kept for air dry after initial washing with double distilled water on the same day. The dried leaves were ground to fine powder using laboratory blender on medium speed. The 1:20 ratio of powder and solvent (ethanol+ water, 50:50) was transferred into reflux apparatus and maintained for six hours at boiling temperature. The extracted solvent was allowed to evaporate to dryness under vacuum on a rotary evaporator at $40^{\circ} \mathrm{C}$. All the extracts were used to filter through a Whattman filter No 1 and were stored at $-20^{\circ} \mathrm{C}$ till usage. The obtained viscous dried extracts were used directly as $2 \mathrm{mg} / \mathrm{mL}, 4 \mathrm{mg} / \mathrm{mL}, 6 \mathrm{mg} / \mathrm{mL}$ and $8 \mathrm{mg} / \mathrm{mL}$ in standard food medium. 


\section{Survivorship}

The antioxidant effect of plants on the life span of adult flies will be studied by feeding the flies ( $\sim 150$ flies from each group) to different diet regimes (control food and different concentration with plant extract) from day 1 of their life cycle (10 flies/vial and 15 vials per group). Flies will be transferred to fresh vials every 10 days and the number of dead flies will be recorded till the last fly's death. Median lifespans were estimated using linear interpolation over scoring intervals.

\section{Developmental time}

Eggs were allowed to grow on different diet regimes (control food and different concentration with plant extract) for $16 \mathrm{~h}$, then permitted to mature at $25^{\circ} \mathrm{C}$. Time to pupation was scored daily.

\section{Fecundity assay}

Fecundity was measured as the mean number of eggs laid per female fly over a 24$\mathrm{h}$ period. $\sim 18 \mathrm{~h}$ after transferring experimental flies to fresh vials, the number of eggs laid in these new vials was counted. The counting was done by eye under a stereo zoom microscope. Differences in egg laying between conditions were analyzed using a nonparametric Wilcoxon rank-sum test and a significance threshold of $\mathrm{P}<0.05$ was used.

\section{Activity of superoxide dismutase (SOD) enzyme}

The approximate 100 flies were homogenized in $1 \mathrm{~mL}$ cold $0.1 \mathrm{M}$ phosphate buffer (pH-7.4) solution and crushed by using mortar-pestle tissue homogenizer, then, centrifuged at 8,000 g for $10 \mathrm{~min}$. The supernatant was collected for enzyme activity. In the method of SOD enzyme estimation, the reduction of NBT (nitroblue tetrazolium) by addition SOD enzyme (tissue homogenized) under aerobic condition was observed. We have made a cocktail of four solutions containing $50 \mu \mathrm{M}$ of sodium carbonate $\left(\mathrm{Na}_{2} \mathrm{CO}_{3}, \mathrm{pH}\right.$ 10), $96 \mu \mathrm{M}$ of NBT, $0.6 \%$ of triton X-100 and $2 \mathrm{mM}$ of hydroxylamine hydrochloride ( $\mathrm{pH}-$ 6 ), then added $0.1 \mathrm{~mL}$ of enzyme supernatant. The enzyme activity was expressed as units $/ \mathrm{min} / \mathrm{mg}$ of protein at A- $560 \mathrm{~nm}$, where one unit of SOD enzyme was expressed as amount of inhibition with rate of reaction by $50 \%$.

\section{Catalase (CAT) assay}

CAT activity in the control and plant extract fed flies will be measured by following the ability of the enzyme to split $\mathrm{H}_{2} \mathrm{O}_{2}$ within 1 min of incubation time. The experiment will be carried out in $15 \mathrm{~mL}$ falcon tube. The assay mixture consisted of $1 \mathrm{~mL}$ of $0.01 \mathrm{M}$ sodium phosphate buffer ( $\mathrm{pH} 7.0$ ), $25 \mu \mathrm{L}$ of sample 10\% homogenate. The final volume will be made $1 \mathrm{~mL}$ by adding distilled water and the tubes will be vortexed. $500 \mu \mathrm{L}$ of $0.2 \mathrm{M}$ hydrogen peroxide (1:3 by volume) will be added followed by $2 \mathrm{~mL}$ dichromate acetic acid ( $5 \%$ of $\mathrm{K}_{2} \mathrm{Cr}_{2} \mathrm{O}_{7}$ with glacial acetic acid). Tubes will be vortexed again and will be kept for boiling for $15 \mathrm{~min}$ and will be cooled under tap water before measuring the optical density (OD). OD will be measured at $570 \mathrm{~nm}$.

\section{Lipid peroxidation}

Malondialdehyde, a lipid peroxidation end product in fly homogenate, was measured according to the method described by Wills (1969) with some minor modifications. A $200 \mathrm{~mL}$ aliquot of fly (without head and wing) homogenate was mixed with $2 \mathrm{~mL}$ of thiobarbituric acid (TBA)-trichloroacetic acid (TCA) reagent $(0.375$ and $15 \%$, respectively). The volume was made up to $3 \mathrm{~mL}$ with distilled water and boiled on a water bath at $95^{\circ} \mathrm{C}$ for $20 \mathrm{~min}$. The solution was then cooled under tap water. The reaction product (TBA-MDA complex) was extracted by adding $3 \mathrm{~mL}$ of $\mathrm{n}$-butanol to the above solution. The absorbance of the pink colored extract in $n$-butanol was measured at $532 \mathrm{~nm}$ 
using a spectrophotometer. The amount of MDA was calculated using a molar extinction coefficient of $1.56^{*} 10^{5} \mathrm{M}^{-1} \mathrm{~cm}^{-1}$ and expressed as nmol of MDA formed per mg of protein.

\section{Results}

\section{Effect of plant extracts on survivorship of Drosophila}

The wild type strain of Drosophila melanogaster from Shimla, India, was reared at $21^{\circ} \mathrm{C}$ on standard food as control and different concentration of plant extracts, i.e. $2 \mathrm{mg} / \mathrm{mL}, 4 \mathrm{mg} / \mathrm{mL}, 6 \mathrm{mg} / \mathrm{mL}$ and $8 \mathrm{mg} / \mathrm{mL}$ for observation of survivorship. The survival was recorded till the all flies died. In the lifespan of Drosophila, it consists of three phases 1) Health lifespan, there will be no natural death, 2) Transition lifespan, it involves slight decline in the adult curve, and 3) Senescent lifespan, that lifespan involves the steady decline in the survivorship curve.

\section{Survivorship}

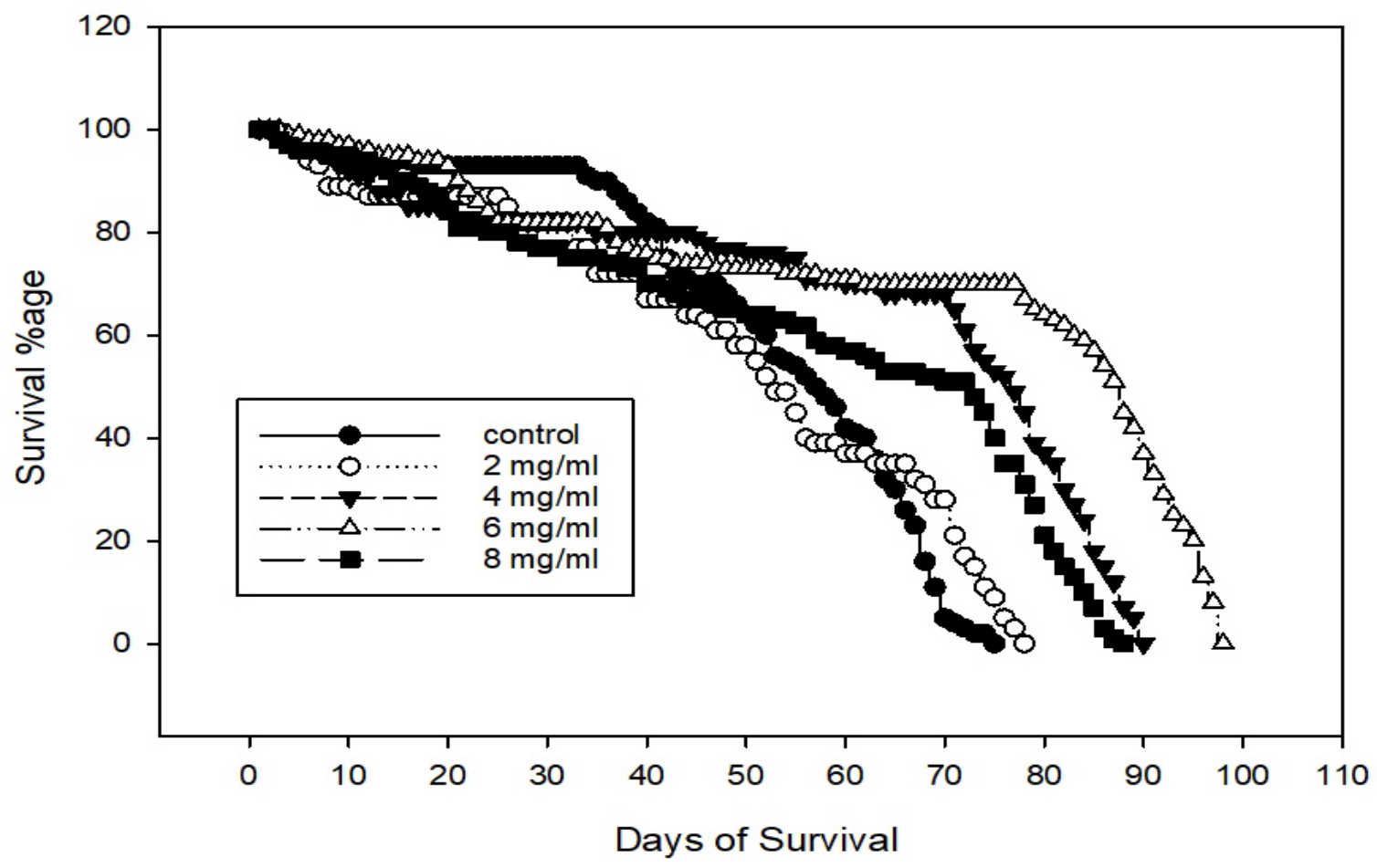

Figure 1. Survivorship curvefor flies reared in different plant extract gradient.

Results from the study (Fgure 1) showed that the control flies have healthy lifespan is about 35 days, 35 to 75 days is about transition lifespan. Using plant extracts of M. koenigii in the standard food medium of Drosophila the lifespan extended accordingly the concentration of plant extracts. The maximum lifespan of flies with above mentioned plant extracts concentration were 75 days, 78 days, 98 days and 88 days, respectively. Hence the results from that study showed that the plant extracts of M. koenigii successfully extended the median lifespan and maximum lifespan by 23 days. 


\section{Developmental delay}

The studies from the literature explained about the correlation between the developmental time and physical health. In Drosophila more will be developmental time more will be body mass and body size. The use of plant extract in diet of M. koenigii at concentration $2 \mathrm{mg} / \mathrm{mL}, 4 \mathrm{mg} / \mathrm{mL}, 6 \mathrm{mg} / \mathrm{mL}$ and $8 \mathrm{mg} / \mathrm{mL}$. There will be a developmental delay, according to respective concentration i.e. from 12 day to 16 day. Hence the developmental time of fly was positively correlated with the increase in the concentration of plant extract food medium and also physical health span (Figure 2).

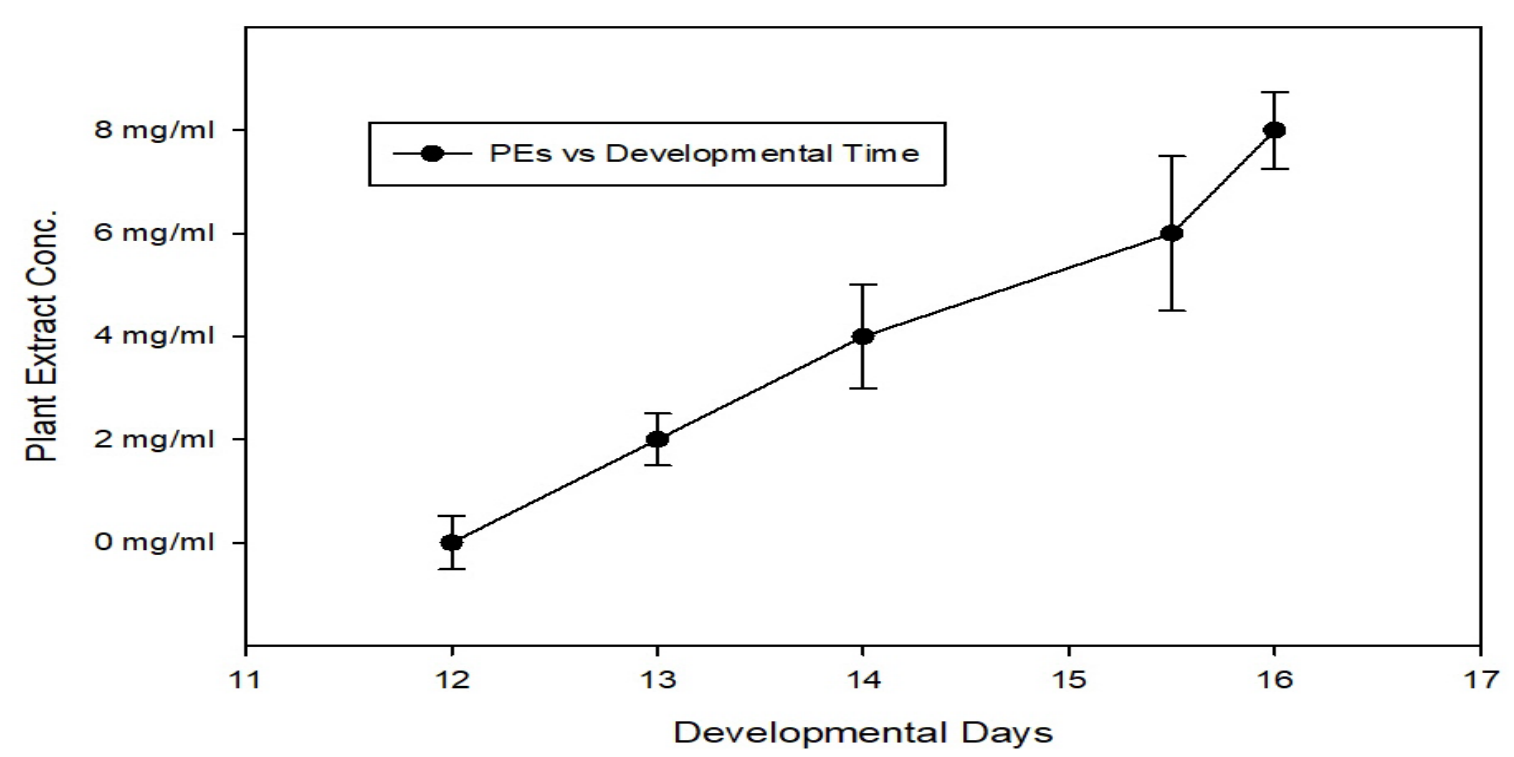

Figure 2. Delay in the developmental time i.e. egg to adult. It expresses developmental time versus plant extract gradient.

\section{Fecundity}

The number of eggs laid by a fly is known as fecundity. We observed significant increase in mean fecundity across the concentration gradient of plant extracts (Figure 3).

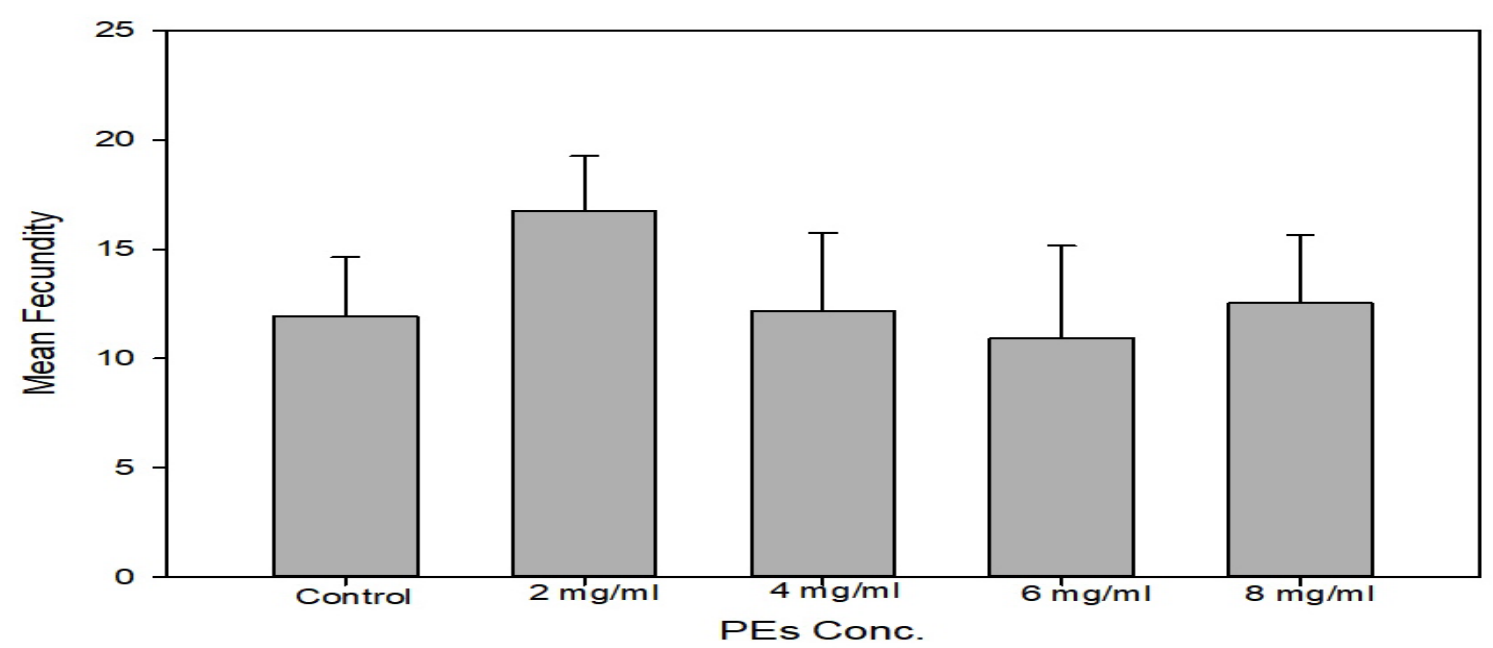

Figure 3. The mean fecundity measured per day egg laid by the fly. It explains the effect on fecundity along the plant extract concentration gradient as mentioned earlier. 


\section{Biochemical assay}

Effect of plant extracts diet on the superoxide dismutase enzyme (SOD). That enzyme activity measures the healthiness of the body. Basically SOD deactivates the highly reactive oxygen free radicals (superoxide) to a less reactive hydrogen peroxide. The SOD activity was measured as units/mg protein. In that experiment as per observations during aging process from 7 day, 21 day and 35 day the activity of SOD was going to decrease. But while used the different concentration of plant extracts of Muraya koenigii in the standard food medium, the activity of SOD enzyme was increased within a limit. These observations showed that during the aging process, free radical generation continuously increasing and damages to the activity of the SOD enzyme. The dietary antioxidant of plant extracts in the food medium removes the oxidative stress by stabilization of free radicals and that relaxation gives a chance to antioxidant enzyme system to increase the activity of the SOD enzyme as these enzymes expressed in the early age of the fly. In these experiments the plant extract concentration of $2 \mathrm{mg} / \mathrm{mL}, 4 \mathrm{mg} / \mathrm{mL}, 6 \mathrm{mg} / \mathrm{mL}$ and $8 \mathrm{mg} / \mathrm{mL}$ successfully removed the burden of oxidative stress and increased the activity of SOD enzyme.

Catalase. We have evaluated the catalase activity in the three age groups i.e. 7 days, 21 days and 35 days old flies along the concentration gradient i.e. control, $2 \mathrm{mg} / \mathrm{mL}, 4 \mathrm{mg} / \mathrm{mL}, 6 \mathrm{mg} / \mathrm{mL}$ and $8 \mathrm{mg} / \mathrm{mL}$. We have found significant increase in the catalase enzyme activity in all age group. The plant extracts concentration $8 \mathrm{mg} / \mathrm{mL}$ showed reduction but although it is significant compare to control group.

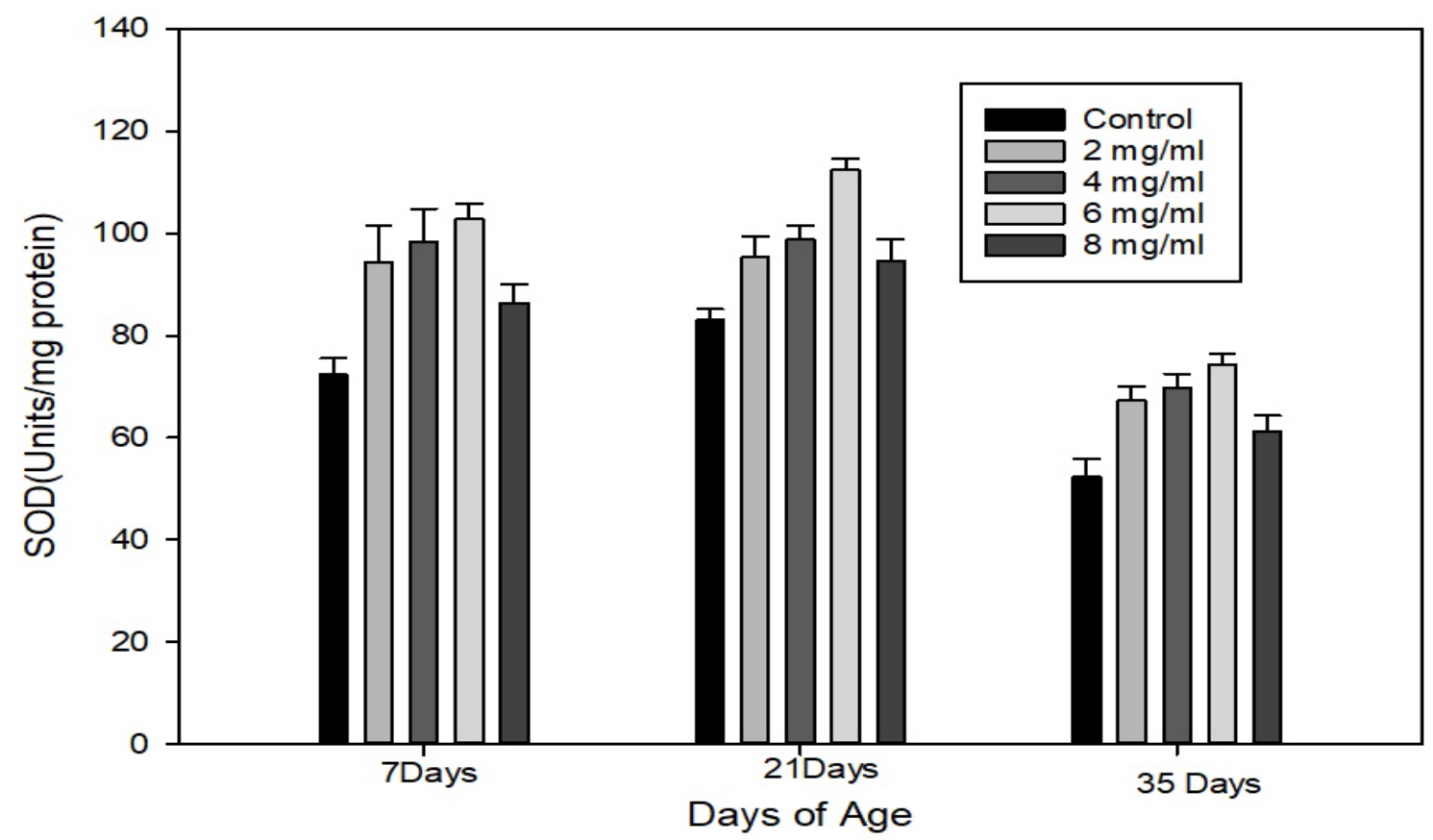

Figure 4. SOD (superoxide dismutase) enzyme activity in three age group, i.e. 7 days, 21 days, and 35 days along with different plant extract gradient concentration. 


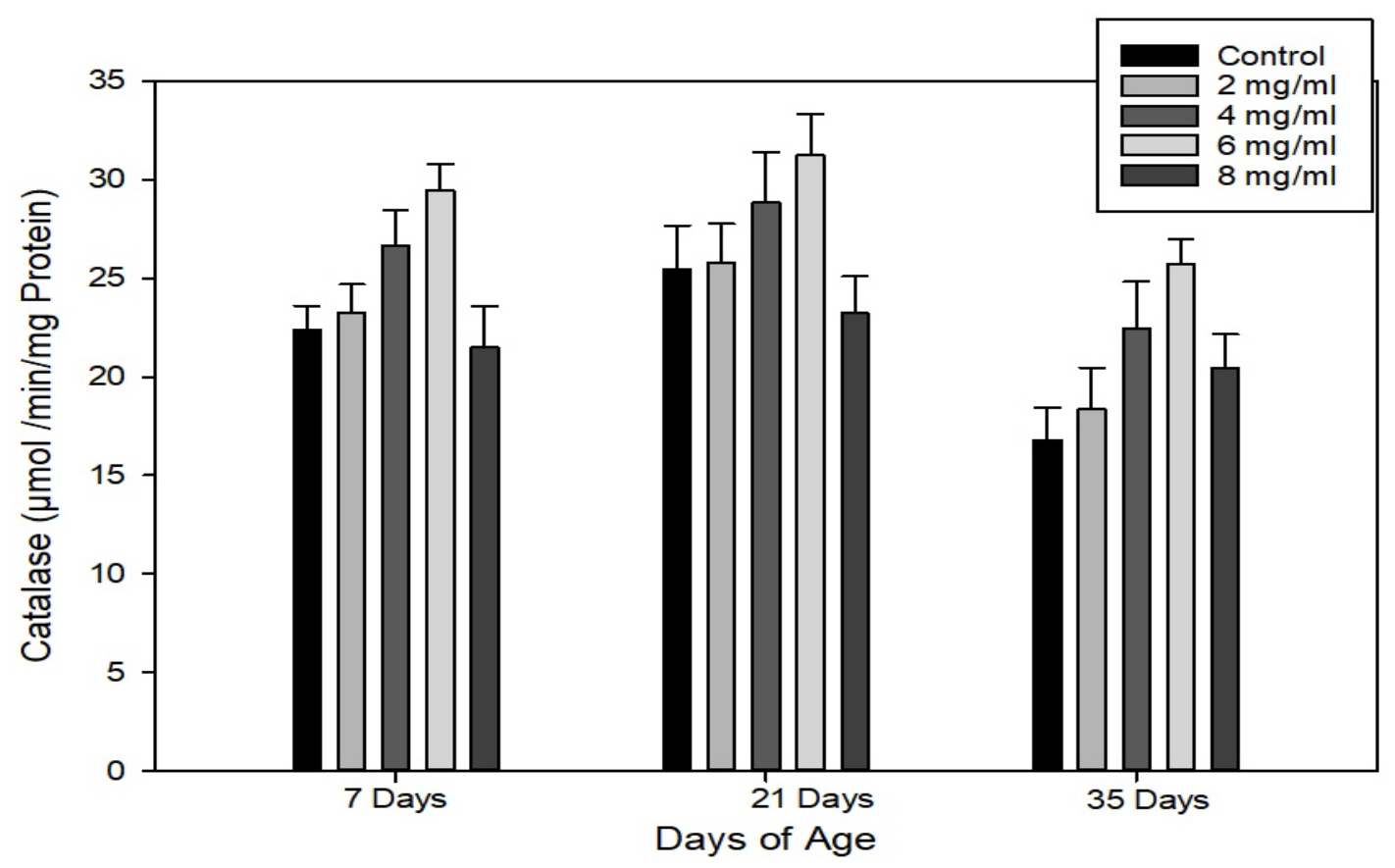

Figure 5. Catalase enzyme activity in three age group, i.e. 7 days, 21 days and 35 days along with different plant extract gradient concentration.

Lipid Peroxidation. It is the peroxidation of lipids of cell membrane result to the formation of malondialdehyde (MDA). We observed the significant decrease in the peroxidation of lipids. Across the concentration gradient in all three age group MDA formation was significantly decrease which showed the suppression the effect of oxidative stress.

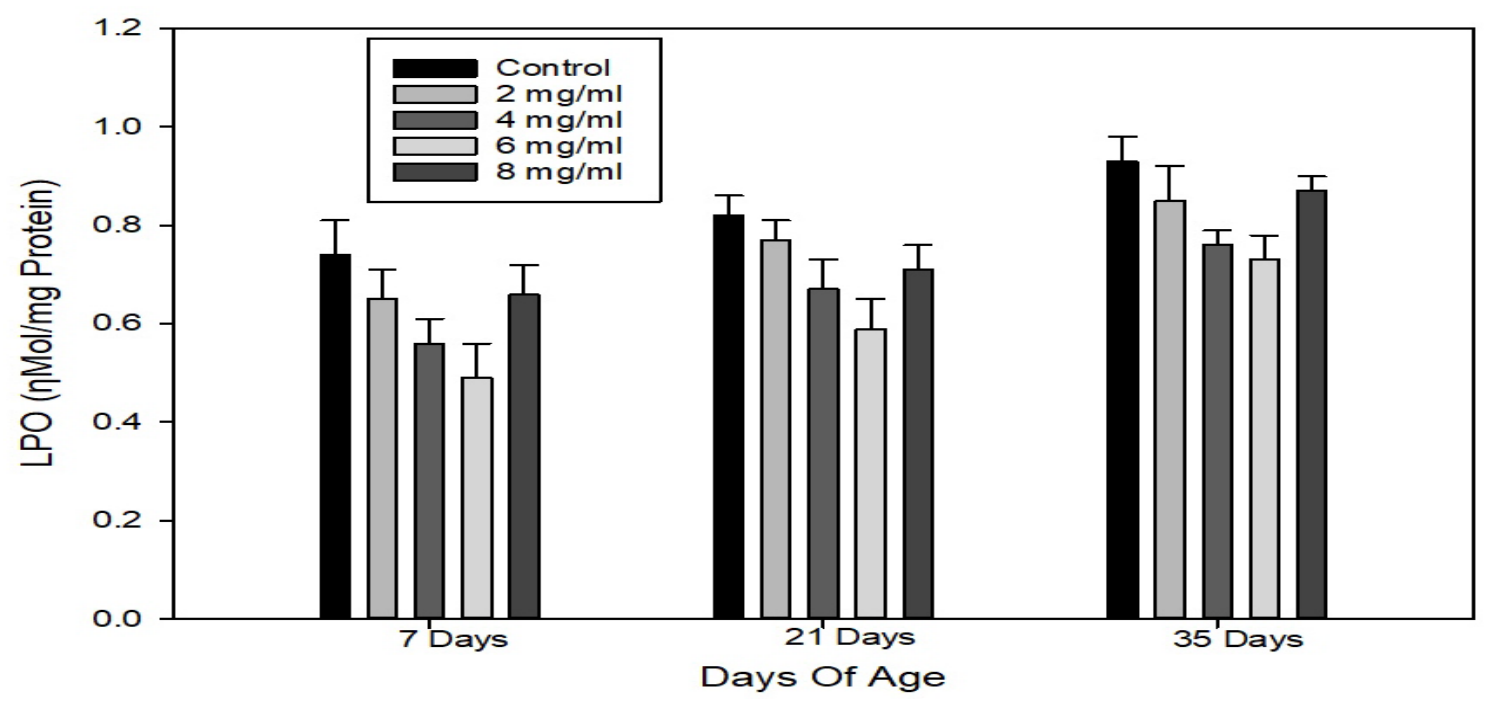

Figure 6. Quantification of LPO (lipid peroxidation) that measures the malondialdehyde (MDA) in three age group, i.e. 7 days, 21 days and 35 days along with different plant extract gradient concentration. 


\section{Discussion and conclusion}

Many studies have evaluated number of natural antioxidants, neutraceuticals and plants which have been identified as free radical scavengers. As stated by free radical theory of aging (FRTA) (Harman, 1956, 1972). The production of free radicals is unavoidable created by livings in anaerobic respiration. Researches on these plant neutraceuticals are of interest to the scientific community. To better understand their antioxidative property it is essential to identify the active ingradients of plant species by both in vivo and ex vivo (Peng et al., 2011, 2012; Zuo et al. 2012, 2013).

The plant M. koenigii has richest source of carbazole alkaloids that has been reported as pharmalogical use as anti-tumor, anti-inflammatory, anti-diabetic and also antioxidant activies (Knolker and Reddy, 2008).

In this study we have successfully evaluated the antioxidant capacity of M. koenigii in the D. melanogaster. The days of survival and fecundity was significantly increased. The oxidative stress markers SOD, catalase and lipid peroxidation also showed the significant result towards the suppression in the formation of free radicals.

\section{Acknowledgement}

This work has been supported by UGC-New Delhi Fellowship. We also thankful to Dr. Vikram Munday for valuable advice on the menuscript.

\section{Conflicts of interest}

Authors declare that they have no conflict of interests.

\section{References}

Bilen, J.; Bonini, N. M. Drosophila as a model for human neurodegenerative disease. Annual Review of Genetics, v. 39, p.153-171, 2005. https://doi.org/10.1146/annurev.genet. 39.110304.095804

Devatkal, S. K.; Thorat, P. R.; Manjunatha, M.; Anurag, R. K. Comparative antioxidant effect of aqueous extracts of curry leaves, fenugreek leaves and butylated hydroxytoluene in raw chicken patties. Journal of Food Science and Technology, v. 49, no. 6, p. 781-785, 2012. https://doi.org/10.1007/s13197-011-0511-0

Gutteridge, J. M.; Halliwell, B. Free radicals and antioxidants in the year 2000. A historical look to the future. Annals of the New York Academy of Sciences, v. 899, no. 1, p. 136147, 2000. https://doi.org/10.1111/j.1749-6632.2000.tb06182.x

Harman, D. Aging: A theory based on free radical and radiation chemistry. Journal of Gerontology, v. 11, no. 3, p. 298-300, 1956. https://doi.org/10.1093/geronj/11.3.298

Harman, D. Free radical theory of aging: Dietary implications. American Journal of Clinical Nutrition, v. 25, no. 8, p. 839-843, 1972. https://doi.org/10.1093/ajcn/25.8.839

Jain, V.; Momin, M.; Laddha, K. Murraya koenigii: An updated review. International Journal of Ayurvedic and Herbal Medicine, v. 2, no. 4, p. 607-627, 2012.

Jafari, M. Drosophila melanogaster as a model system for the evaluation of anti-aging compounds. Fly, v. 4, no. 3, p. 253-257, 2010. https://doi.org/10.4161/fly.4.3.11997 
Peng, C.; Chan, H. Y. E.; Huang, Y.; Yu, H.; Chen, Z. Apple polyphenols extend the mean lifespan of Drosophila melanogaster. Journal of Agricultural and Food Chemistry, v. 59, no. 5, p. 2097-2106, 2011. https://doi.org/10.1021/jf1046267

Peng, C.; Zuo, Y.; Kwan, K. M.; Liang, Y.; Ma, K. Y.; Chan, H. Y.; Huang, Y.; Yu, H.; Chen, Z. Y. Blueberry extract prolongs lifespan of Drosophila melanogaster. Experimental Gerontology, v. 47, no. 2, p. 170-178, 2012. https://doi.org/10.1016/j.exger.2011.12.001

Sindhu, R. K.; Arora, S. Phytochemical and pharmacognostical studies on Murraya koenigii L. Spreng roots. Drug Invention Today, v. 4, p. 325-336, 2012.

Zahin, M.; Aqil, F.; Husain, F. M. Ahmad, I. Antioxidant capacity and antimutagenic potential of Murraya koenigii. BioMed Research International, v. 2013, Article ID 263509, 2013. https://doi.org/10.1155/2013/263509

Zuo, Y.; Peng, C.; Liang, Y. T.; Ma, K. Y.; Yu, H.; Chan, H. Y. E.; Chen, Z. Y. Black rice extract extends the lifespan of fruit flies. Food \& Function, v. 3, no. 12, p. 1271-1279, 2012. https://doi.org/10.1039/c2fo30135k

Zuo, Y.; Peng, C.; Liang, Y.; Ma, K. Y.; Chan, H. Y.; Huang, Y.; Chen, Z. Y. Sesamin extends the mean lifespan of fruit flies. Biogerontology, v. 14, no. 2, p.107-119, 2013. https://doi.org/10.1007/s10522-012-9413-4

License information: This is an open-access article distributed under the terms of the Creative Commons Attribution License, which permits unrestricted use, distribution, and reproduction in any medium, provided the original work is properly cited. 